\title{
Comparison of the effects of muscle-strengthening exercise using free weights and elastic resistance bands to maximum voluntary isometric contraction of the biceps brachii muscle on untrained subjects
}

\author{
Anang Silahudina, Sri Mardjiati Mei Wulan a, I Putu Alit Pawana ${ }^{\text {a }}$ Indrayuni Lukitra \\ Wardani $^{\mathrm{a}}$, Lydia Arfianti ${ }^{\mathrm{a}}$, Soenarnatalina Melaniani ${ }^{\mathrm{a}}$

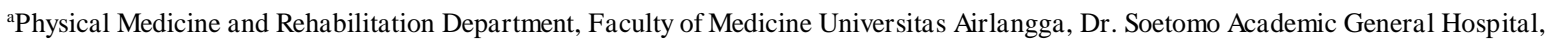 \\ Surabaya, Indonesia \\ Corresponding author: meiwulan21@gmail.com
}

\begin{abstract}
Background: Impaired muscle performance, muscle weakness and atrophy, even sarcopenia (reduced muscle mass and strength) can be caused by injury, disease, immobilization, disuse, and inactivity. Resistance training is an appropriate therapeutic intervention to increase integrated muscle power, strength, and endurance during functional movement, to reduce the risk of injury or re-injury, and to improve physical performance.
\end{abstract}

Objective: To compare the effectiveness of free weights (dumbbells) and elastic resistance bands in increasing the biceps brachii muscle strength on untrained subjects during four weeks of training.

\begin{abstract}
Methods: The study was conducted from February to March 2021. Twenty-four men with low and moderate activity levels were recruited and randomized into the dumbbell group (DB) and the elastic resistance bands (ERB) group. Each group was given a biceps brachii muscle strengthening exercise program for 4 weeks. Maximum voluntary isometric contraction (MVIC) of biceps brachii muscle was collected before and after treatment.
\end{abstract}

\begin{abstract}
Results: There was a significant difference in the MVIC value before and after 4 weeks of exercise in the DB group (right $p$-value 0.002 and left p-value 0.003) and the ERB group (right p-value 0.000 and left p-value 0.001), there was no difference significant difference in MVIC of the right and left biceps brachii muscles before and after 4 weeks of exercise between the two groups (right p-value 0.453 and left 0.714).
\end{abstract}

Conclusion: Free weights and elastic resistance bands show the same effect in increasing MVIC on untrained subjects

Keywords: Muscle strengthening exercises; elastic resistance bands; dumbbells; maximum voluntary isometric contraction (MVIC); Indonesia

\section{Introduction}

Impaired muscle performance, muscle weakness, and atrophy, even sarcopenia (reduced muscle mass and strength) can be caused by injury, disease, immobilization, disuse, and inactivity (Kisner et al., 2012; Ciolac et al., 2016). In general, there are two methods of assessing physical activity, namely the subjective method and the objective method. The subjective method relies on individuals to record the activities they are doing at that time or remember previous activities, one of which is the IPAQ-SF (International Physical Activity Questionnaire-Short Form) questionnaire. The objective method is to measure one or more biosignals, such as acceleration, heart rate, or other indicators of physical activity or energy expenditure (Strath et al., 2013).

The key elements of muscles are power, strength and endurance. Impaired muscle capacity increases the risk of dysfunction, which leads to limited functional activities and participation. A sedentary lifestyle puts people at risk of decreased muscle performance, injury or impaired function. Resistance training is an appropriate therapeutic intervention that can increase overall muscle power, strength, and endurance during functional exercise to reduce injury and improve physical performance (Kisner et al., 2012).

There are various methods for measuring and evaluating the contractile and biomechanical components of skeletal muscle. The electrical and mechanical activity of muscles can be monitored and recorded as maximum voluntary isometric contraction (MVIC) using surface electromyography. Surface EMG is a non-invasive examination that can be used to determine motor function activity (Dordevic et al., 2011; Esposito et al., 2018; Lee et al., 2016, Visser et al., 2003).

The equipments that are often used for strengthening exercises with free weights are dumbbells, barbells, weight-plates, 
cable pulleys, or pneumatic resistance (Kisner et al., 2012; Wilder et al., 2016). Resistance exercises with elastic bands are an alternative choice, light weight, do not need a large space, easy to store or carry, but produce the same muscle activation as conventional resistance exercise equipment (Andersen et al., 2010; G higialeri et al., 2010). al., 2010; Ramos et al., 2014; Aboodarda et al., 2016; Silva., 2016; de Oliveira et al., 2017; Bergquist, 2018; Lopes et al., 2019). Ramos et al stated that exercise with elastic resistance bands had a better effect than exercise with conventional equipment (Ramos et al., 2014).

In Indonesia, elastic bands have not been widely used for strengthening exercises, so researchers want to compare the effectiveness of elastic resistance bands and conventional resistance equipment in increasing muscle strength.

\section{Methods}

This research was conducted for 4 weeks at Physical Medicine and Rehabilitation outpatient clinic Dr. Soetomo Academic General Hospital in February-March 2021. The research subjects were 24 people, which were divided into two groups. Twelve people in the free weights (dumbells) group and 12 people in the elastic resistance bands group for strengthening the biceps brachii muscles. The load given to the subject is at least $60 \%$ of the 1-repetitive maximum (1-RM) of the biceps brachii muscle with 3 sets of 8-12 repetitions, 2 times a week, based on ACSM guidelines (Riebe, 2018). MVIC data collection in both groups was carried out before and after the intervention. MVIC data retrieval using a surfaceEMG device (MESPEC 4000 System (Mega Electronics Ltd.) at the middle of the right and left side of the biceps brachii muscle, according to the protocol from SENIAM (Stegemen et al., 2007).

This research has obtained an ethical certificate from the ethics committee of Dr. Soetomo Academic General Hospital Surabaya with the code number 0091/KEPK/XI/2020. All data were analyzed using SPSS version 23.

\section{Results}

All research subjects were able to complete the exercise program.

Table 1. Basic characteristics of subjects before treatment

\begin{tabular}{llll}
\hline Variable & $\begin{array}{l}\text { Dumbbell group } \\
(\mathbf{n}=12)\end{array}$ & $\begin{array}{l}\text { Elastic resistance } \\
\text { bands group }(\mathbf{n = 1 2})\end{array}$ & p-value * \\
\hline Age (years) & $30,08 \pm 1,39$ & $31,83 \pm 1,07$ & $0,229^{*}$ \\
\hline Body weight $(\mathbf{k g})$ & $77,29 \pm 5,68$ & $66,67 \pm 3,07$ & $0,136^{*}$ \\
\hline Body height $(\mathbf{m})$ & $1,70 \pm 1,75$ & $1,69 \pm 1,94$ & $0,808^{*}$ \\
\hline MVIC $(\mathbf{m V})$ right & $0,41 \pm 0,76$ & $0,37 \pm 0,05$ & $0,436^{*}$ \\
\hline MVIC (mV) left & $0,38 \pm 0,08$ & $0,30 \pm 0,04$ & $0,051^{*}$ \\
\hline
\end{tabular}

*Homogeneity test using Levene's test

Table 1 shows that the two groups obtained homogeneous data on age, weight, height, and right and left MVIC values.

Table 2. Basic characteristics and normality test of subjects in the Dumbbell group

\begin{tabular}{lllll}
\hline Variable & BEFORE & p-value* & AFTER & p-value* \\
\hline Age (years) & $30,08 \pm 1,39$ & $0,077^{*}$ & & \\
\hline Body weight $(\mathbf{k g})$ & $77,29 \pm 5,68$ & $0,087^{*}$ & & \\
\hline Body height $(\mathbf{m})$ & $1,70 \pm 1,75$ & $0,212^{*}$ & & \\
\hline MVIC $(\mathbf{m V})$ right & $0,41 \pm 0,76$ & $0,059^{*}$ & $0,64 \pm 0,11$ & 0,042 \\
\hline MVIC (mV) left & $0,38 \pm 0,08$ & 0,020 & $0,59 \pm 0,11$ & 0,010
\end{tabular}

* Normality test using Shapiro-Wilk

Table 2 shows the number of subjects analyzed in the Dumbbell group. Normal distribution was shown in the variables of age, body weight, body height, and MVIC (Maximum voluntary isometric contraction) right before exercise. Abnormal distribution was found in the right MVIC after exercise and the left MVIC before and after exercise.

Table 3. Basic characteristics and normality test of subjects in the Elastic Resistance Bands group

\begin{tabular}{lllll}
\hline Variable & BEFORE & p-value* & AFTER & p-value* \\
\hline Age (years) & $30,08 \pm 1,39$ & $0,077^{*}$ & & \\
\hline Body weight $(\mathbf{k g})$ & $77,29 \pm 5,68$ & $0,087^{*}$ & & \\
\hline Body height $(\mathbf{m})$ & $1,70 \pm 1,75$ & $0,212^{*}$ & & \\
\hline MVIC $(\mathbf{m V})$ right & $0,37 \pm 0,05$ & $0,077^{*}$ & $0,59 \pm 0,06$ & $0,229^{*}$ \\
\hline MVIC (mV) left & $0,30 \pm 0,04$ & $0,160^{*}$ & $0,53 \pm 0,06$ & $0,276^{*}$ \\
\hline
\end{tabular}

* Normality test using Shapiro-Wilk

Table 3 shows normal distribution was shown in the variables of age, body weight, body height, MVIC (Maximum voluntary isometric contraction) right and left before and after exercise with elastic resistance bands. 
Table 4. MVIC values before and after exercise in the elastic resistance bands group

\begin{tabular}{llll}
\hline & \multicolumn{3}{l}{ Elastic Resistance Bands Group } \\
\hline & Sebelum & Setelah & p-value \\
\hline MVIC (mV) right & $0,37 \pm 0,19$ & $0,59 \pm 0,23$ & 0,000 \\
\hline MVIC (mV) left & $0,30 \pm 0,14$ & $0,54 \pm 0,21$ & 0,001 \\
\hline
\end{tabular}

*Significant if p-value $<0.05$

Table 4 shows that there is a significant difference in the right MVIC before and after 4 weeks of exercise in the elastic resistance bands group (p-value 0.000). On the left MVIC value there was also a significant difference before and after 4 weeks of exercise ( $\mathrm{p}$ value 0.001 ).

Table 5. MVIC values before and after exercise in the dumbbell group

\begin{tabular}{llll}
\hline & \multicolumn{2}{l}{ Dumbbell Group } & \\
\hline & Sebelum & Setelah & p-value \\
\hline MVIC (mV) right & $0,41 \pm 0,76$ & $0,64 \pm 0,11$ & 0,002 \\
\hline MVIC (mV) left & $0,38 \pm 0,08$ & $0,59 \pm 0,11$ & 0,003 \\
\hline
\end{tabular}

*Significant if $\mathrm{p}$-value $<0.05$

Table 5 shows a significant difference in the right MVIC before and after 4 weeks of exercise in the dumbbell group (pvalue 0.002). There was also a significant difference in left MVIC before and after 4 weeks of exercise in the dumbbell group (p-value 0.003).

Table 6. Comparison of the difference in MVIC before and after exercise between the two groups

\begin{tabular}{lccc}
\hline & Dumbbell $(\mathbf{n}=\mathbf{1 2})$ & $\begin{array}{c}\text { Elastic Resistance bands } \\
(\mathbf{n = 1 2})\end{array}$ & p-value \\
\hline MVIC (mV) right & $0,23 \pm 0,4$ & $0,22 \pm 0,2$ & 0,453 \\
\hline MVIC (mV) left & $0,22 \pm 0,4$ & $0,24 \pm 0,3$ & 0,714 \\
\hline
\end{tabular}

*Significant if p-value $<0.05$

Table 6 shows no significant difference in the MVIC difference between the right and left biceps brachii muscles before and after 4 weeks of exercise between the two groups (right p-value 0.453 and left 0.714 ).

Table 7. Statistical Data for Calculation of Effect Size

\begin{tabular}{lcc}
\hline \multicolumn{1}{c}{ Variabel } & Effect size & Effect \\
\hline Right MVIC ERB & 1.05123 & Very Strong \\
\hline Right MVIC DB & 0.71707 & Strong \\
\hline Left MVIC ERB & 1.30651 & Very Strong \\
\hline Left MVIC DB & 0.6584 & Strong \\
\hline
\end{tabular}

$\mathrm{MVIC}=$ Maximum voluntary isometric contraction, $\mathrm{ERB}=$ Elastic resistance bands, $\mathrm{DB}=\mathrm{Dumbbell}$

$d=0-0,2$ : Small effect; $d>0,2-0,5$ : Moderate effect; $d>0,5-0,8$ : Strong effect; $d>0,8$ : Very strong effect

Table 7 shows the very strong effect of the ERB group on the right and left side MVIC values. There was a strong effect on the DB group on the right and left side of MVIC values.

\section{Discussion}

Resistance training produced in an increase in muscle size, muscle strength, and muscle power through several mechanisms, ranging from skeletal muscle hypertrophy and changes in muscle architecture to neural adaptations such as increased motor unit activation and supraspinal adaptation (Kristensen et al., 2012).

The adaptation of the body's physiology to muscle strengthening exercises is an increase in muscle recruitment that occurs in the first 2 weeks, after which there will be an increase in muscle mass after 4 weeks of resistance training (Hoffman et al., 2010). Surface electromyography has become a kinesiology-based tool to examine muscle function during certain movements, and muscle activity, muscle strength, muscle fatigue/fatigue, and type of muscle contraction (Heikkinen., 2011; Kuthe et al., 2018). sEMG electrodes are placed on the skin surface to record the electrical activity of the muscles (Burhan et al., 2017).

The homogenicity test showed that there were no significant differences in the characteristics of age, weight, height, and right and left MVIC values between the two groups in this study. Based on the characteristics of the age of the subjects is $30.08+1.39$ years. According to Volpi et al and Pereira et al research, muscle mass will decrease by about 3-8\% per decade after the age of 30 years, so it is necessary to give resistance training to maintain and increase muscle mass (Volpi et al., 2004; Pereira et al. , 2013).

There were significant differences in MVIC values before and after 4 weeks of exercise in the elastic resistance bands group and strong effect was found on the right and left-sided MVIC values. The result shows that the biceps brachii resistance exercise using elastic resistance bands can increase the MVIC value. In the meta-analysis of Lopes et al., stated that the final 
results of muscle strength and power after resistance training with elastic resistance bands would be similar to exercises with free weights (dumbbells). A very strong effect was found in the ERB group on right and left-side MVIC values, changes in MVIC after muscle strengthening exercises were associated with adaptive modifications in the neuromuscular system that occurred in the first 2-4 weeks of a strengthening exercise program (Kidgell et al., 2010; Jamal et al., 2012).

There were significant results on the MVIC value in the dumbbell group. Dumbbells are one of the resistance tools used to increase muscle mass. The patients controlled the movement completely but need time to learn proper alignment and movement pattern. Dumbbells are resistance equipment that applies a constant weight load at the whole range of motions of the joints. Most exercises with free weights must be performed slowly to minimize acceleration and momentum and prevent uncontrolled, end-range movements that could compromise patient safety (Kisner et al., 2012). Strengthening exercises will increase corticospinal excitability because the subject performs each repetition in a controlled manner (Kidgell et al., 2010). Increased excitability of corticospinal cells is projected to spinal motor neurons that control muscles and cause an increase in muscle strength. In addition, muscle hypertrophy that is trained will also lead to an increase in muscle strength and an increase in MVIC (Kidgell et al., 2010; Kristensen et al., 2012).

\section{Conclusion}

Free weights and elastic resistance bands show the same effect in increasing MVIC on untrained subjects. Further research is needed to monitor the subject's physical activity and nutrition because higher physical activity and inadequate nutrition can affect the resistance training results.

\section{References}

Aboodarda, Saied Jalal, Phillip A. Page, and David George Behm. "Muscle activation comparisons between elastic and isoinertial resistance: A metaanalysis." Clinical Biomechanics 39: 52-61. 2016

Andersen, L. L., Andersen, C. H., Mortensen, O. S., Poulsen, O. M., Bjørnlund, I. B. T., \& Zebis, M. K. Muscle activation and perceived loading during rehabilitation exercises: comparison of dumbbells and elastic resistance. Physical therapy, 90(4), 538-549. 2010

Bergquist, Ronny. Assessment of muscle activity using elastic resistance in strength exercise. MS thesis. NTNU, 2015.

Burhan, N., Kasno, M. A., Ghazali, R., Said, M. R., Abdullah, S. S., \& Jali, M. H. (2017). Analysis of the biceps brachii muscle by varying the arm movement level and load resistance band. Journal of healthcare engineering, 2017.

Ciolac, Emmanuel Gomes, and José Messias Rodrigues-da-Silva. "Resistance training as a tool for preventing and treating musculoskeletal disorders." Sports Medicine 46.9: 1239-1248. 2016

Đorđević, Srđan, Sašo Tomažič, Marco Narici, Rado Pišot, and Andrej Meglič. "In-vivo measurement of muscle tension: dynamic properties of the MC sensor during isometric muscle contraction." Sensors 14, no. 9 (2014): 17848- 17863.

de Oliveira, P.A., Blasczyk, J.C., Junior, G.S., Lagoa, K.F., Soares, M., de Oliveira, R.J., Gutierres Filho, P.J.B., Carregaro, R.L. and Martins, W.R.. Effects of elastic resistance exercise on muscle strength and functional performance in healthy adults: a systematic review and meta-analysis. Journal of physical activity and health, 14(4), pp.317-327. 2017

Ghigiarelli, J. J., Nagle, E. F., Gross, F. L., Robertson, R. J., Irrgang, J. J., \& Myslinski, T. The Effects of a 7-Week Heavy Elastic Band and Weight Chain Program on Upper-Body Strength and Upper-Body Power in a Sample of Division 1-AA Football Players. Journal of Strength and Conditioning Research, 23(3), 756- 764. doi:10.1519/jsc.0b013e3181a2b8a2. 2009

Heikkinen, Lori. "Non-invasive physiological monitoring of exercise and fitness." Neurological Research 33.1: 3-17. 2011

Hoffman, Martin. Kraemer, William. Judelson, Daniel. Frontera, Walter. Therapeutic exercise in DeLisa's Physical Medicine and Rehabilitation principle and practice, Fifth edition. Philadelphia : Lippincott Williams \& Wilkins. P.1639-1641s. 2010

Jamal, Muhammad Zahak. "Signal acquisition using surface EMG and circuit design considerations for robotic prosthesis." Computational Intelligence in Electromyography Analysis-A Perspective on Current Applications and Future Challenges 18: 427-448. 2012

Kidgell, Dawson J., Mark A. Stokes, Troy J. Castricum, and Alan J. Pearce. "Neurophysiological responses after short- term strength training of the biceps brachii muscle." The Journal of Strength \& Conditioning Research 24, no. 11 (2010): 3123-3132.

Kisner, C., Colby, L. A., \& Borstad, J. Therapeutic exercise: foundations and techniques. $7^{\text {th }}$ edition. Fa Davis. P.157- 182.2017.

Kristensen, J. and Franklyn-Miller, A. Resistance training in musculoskeletal rehabilitation: a systematic review. British journal of sports medicine, 46(10), pp.719-726.) 2012

Kuthe, Chetan D., Rashmi V. Uddanwadiker, and Alankar A. Ramteke. "Surface electromyography based method for computing muscle strength and fatigue of biceps brachii muscle and its clinical implementation." Informaticsin Medicine Unlocked 12: 34-43. 2108

Lee, Sang-Yeol, and Marg-Eun Jo. "Comparison of maximum voluntary isometric contraction of the biceps on various posture and respiration conditions for normalization of electromyography data." Journal of physical therapy science 28, no. 11 (2016): 3007-3010.

Lopes, J.S.S., Machado, A.F., Micheletti, J.K., De Almeida, A.C., Cavina, A.P. and Pastre, C.M., Effects of training with elastic resistance versus conventional resistance on muscular strength: a systematic review and meta- analysis. SAGE open medicine, 7, p.2050312119831116) 2019

Pereira, A.F., Silva, A.J., Costa, A.M., Monteiro, A.M., Bastos, E.M. and Marques, M.C., Muscle tissue changes with aging. Acta medica portuguesa, 26(1), pp.51-55. 2013

Ramos, E. M. C., de Toledo-Arruda, A. C., Fosco, L. C., Bonfim, R., Bertolini, G. N., Guarnier, F. A., ... Ramos, D. The effects of elastic tubing-based resistance training compared with conventional resistance training in patients with moderate chronic obstructive pulmonary disease: a randomized clinical trial. Clinical Rehabilitation, (2014) 28(11), 1096-1106. doi:10.1177/0269215514527842

Riebe, Deborah. ACSM's Guidelines for Exercise Testing and Prescription. Tenth edition. Wolters Kluwer. P.249-256. 2018.

Silva BS, Gobbo LA, Freire AP, Trevisan IB, Silva IG, Ramos EM. Effects of a resistance training with elastic tubing in strength, quality of life and dypsnea in patients with chronic obstructive pulmonary disease. Journal of Physical Education. 2016 Sep 26;27.

Stegeman, D., and H. Hermens. "Standards for surface electromyography: The European project Surface EMG for non- invasive assessment of muscles (SENIAM)." (2007)

Strath SJ, Kaminsky LA, Ainsworth BE, Ekelund U, Freedson PS, Gary RA, Richardson CR, Smith DT, Swartz AM. Guide to the assessment of physical activity: clinical and research applications: a scientific statement from the American Heart Association. Circulation. 2013 Nov 12;128(20):2259-79.

Visser J, Mans E, de Visser M, et al.: Comparison of maximal voluntary isometric contraction and hand-held dynamometry in measuring muscle strength of patients with progressive lower motor neuron syndrome. Neuromuscul Disord, 2003, 13: 744-750

Volpi, E., Nazemi, R. and Fujita, S., 2004. Muscle tissue changes with aging. Current opinion in clinical nutrition and metabolic care, 7(4), p.405.

Wilder R.P, Jenkins J.G., Panchang Preeti, Statuta Siobhan. Chapter 15: Therapeutic Exercise. In: Braddom RL, ed. Physical Medicine and Rehabilitation. $5^{\text {th }}$ ed. Philadelphia, PA: W.B. Saunders Co.; 2016. P.321-333. 